\title{
Are Nutrition and Dietetics Students More Prone to Eating Disorders Related Attitudes and Comorbid Depression and Anxiety than Non-Dietetics Students?
}

\author{
Aliye Ozenoglu1 ${ }^{*}$, Gökce Unal1, Aydan Ercan², Hatice Kumcagiz ${ }^{3}$, Kamil Alakus ${ }^{4}$ \\ ${ }^{1}$ Nutrition and Dietetics Department, Samsun Health School, Ondokuz Mayis University, Samsun, Turkey \\ ${ }^{2}$ Nutrition and Dietetics Department, Faculty of Health Science, Baskent University, Ankara, Turkey \\ ${ }^{3}$ Counseling and Guidance Department, Faculty of Education, Ondokuz Mayis University, Samsun, Turkey \\ ${ }^{4}$ Statistics Department, Faculty of Science and Literature, Ondokuz Mayis University, Samsun, Turkey \\ Email: *aozenoglu@yahoo.com, *aozenoglu@omu.edu.tr
}

Received 29 August 2015; accepted 26 October 2015; published 29 October 2015

Copyright (C) 2015 by authors and Scientific Research Publishing Inc.

This work is licensed under the Creative Commons Attribution International License (CC BY).

http://creativecommons.org/licenses/by/4.0/

(c) (i) Open Access

\begin{abstract}
It was aimed to investigate the eating attitudes and its relationships with anxiety and depression at Nutrition and Dietetics students. Students of Nutrition and Dietetics Departments were included in study group (n: 135) and non-medical students (n: 69) were in control group. Eating attitudes test (EAT-40), Beck Depression Inventory (BDI), and Beck Anxiety Inventory (BAI) were applied to all students and some anthropometric measurements were taken. Body mass index (BMI) and percent of body fat were higher at students in study group than students in control group. There were no significant differences between groups with respect to EAT, BDI and BAI scores. But, BMI and body fat percentage in girls were significantly lower than boys. Both EAT and BDI scores were significantly higher in girls than boys but BAI scores did not differ significantly. It was concluded that students training on Nutrition and Dietetics might have obsessions related to body image. But results of this study revealed that especially young women were more susceptible to eating disorders and depression.
\end{abstract}

\section{Keywords}

Eating Attitudes, Anxiety, Depression, Dietetic Students

\footnotetext{
${ }^{*}$ Corresponding author.
} 


\section{Introduction}

Young adulthood, especially during the transition to a college setting, can be a vulnerable time for development and/or continuation of eating disorders when parents generally have little control or influence on eating behaviors [1] [2]. In a review by Hoek et al. [3], an average prevalence rate for anorexia nervosa of $0.3 \%$ was found for young females. The prevalence rates for bulimia nervosa were $1 \%$ and $0.1 \%$ for young women and young men, respectively. In a study significantly more female (3.2\%) than male (1.2\%) students had abnormal eating attitudes. Significant relationships were observed among eating attitudes, body shape concern, social anxiety, depression, and body mass index [4].

It has been reported that eating habits of adolescents are affected with factors such as family problems, low self-esteem, obesity, weight gain and dealing with foods [5] [6]. It has observed that most of the young people affected by any existing health problems either at himself or at his parents turn to receive education in the field of health. Furthermore, it is also known that young people who have problems with body image give more attention to such issues as nutrition, diet and weight loss. It has been demonstrated that various pathological disorders such as depression, anxiety and low self-esteem may coexist with eating disorders [7]-[9].

It is known that the choice of profession is influenced by the individual's past life experiences. Choosing a career is related to early childhood and the subconscious factors. According to psychoanalytic approach, career choice is influenced by the subconscious. Professional behavior in adulthood is caused by early childhood. The strong bond between man and life is accepted as "business". According to Freud, "business is the individual's connection with reality". Individual's business/profession is the most important element in defining and forming his identity. The work done gives a certain way to the individual's thoughts and life [10].

In this study, starting from the idea that young people who have problems with body image and who are interested in nutrition and dietary issues may have preferred to study in this area, we aim to investigate the eating attitudes and its relationship with anxiety and depression among university students training on Nutrition and Dietetics in Turkey.

\section{Methods}

This study was conducted on students beginning their university education at the Nutrition and Dietetics Department of one state and one private university in the 2012-2014 academic years. The control group was selected randomly from students of non-medical departments training in first classes.

\subsection{Sample Population}

A total of 204 students (135 in study group and 69 in control group) who accepted to participate in the study and signed the consent form were included to this study. Only new students who started their first year at the university were accepted because we paid attention to participants' not to take any formal training on health, nutrition and psychology at undergraduate level.

\subsection{Test Scales}

A questionnaire on demographic characteristic and family history and some psychometric tests namely Beck Depression Inventory (BDI), Eating Attitudes Test (EAT-40) and Beck Anxiety Inventory (BAI) were applied to all participants.

\subsubsection{Eating Attitudes Test-40 (EAT-40)}

EAT measures possible disorders of eating behaviour existing in normal individual as well as meal-related behaviour and attitudes of Anorexia Nervosa (AN) patients. EAT is thought to be a good screening tool for eating disorders. It was developed by Garner and Grafinkel [11]. Although EAT was originally developed to screen and assess the symptoms of anorexia, it has been used in non clinical samples as a general screening measure for disordered eating attitudes. EAT-40 consisted of 40 items with a six-point Likert scale. The rating range from "always" to "never" with three points for "always", two points for "very often" and one point for "often". The rest of the choices are rated zero. The cut-off score for the scale is 30 . Scores between 30 and 32 are accepted as sub-clinical group scores. Scores of 33 and above mean that a person probably has pathological eating symptoms. EAT-40 was adapted to Turkish by Savasır and Erol [12]. 


\subsubsection{Beck Depression Inventory (BDI)}

Inventory was developed by Beck in 1961 [13]. It measures physical, emotional, cognitive and motivational symptoms seen in depression. It was developed to determine the level of depression of subjects and applied to healthy and psychiatric patient group. Validity and reliability study was made by Hisli [14] and cut-off score were accepted as 17. It contains a total of 21 self assessment sentences and provides four-point Likert-type measurement. Each item is scored 0 - 3 and total score ranges from 0 to 63 . High total scores show the severity of depression.

\subsubsection{Beck Anxiety Inventory (BAI)}

It has been developed by Beck and colleagues [15]. Validity and reliability study was made by Ulusoy and colleagues in our country [15]. It measures the frequency of anxiety symptoms that the individual experienced. It is a Likert-type self-assessment scale consisting of 21 item and scored $0-3$. High total scores indicate the severity of anxiety of individual [16].

\subsection{Personal Information}

A questionnaire was prepared to get information on sociodemographic data of the students (age, gender, place of birth, education level, marital status, health status, the place they live, family information).Some anthropometric measurements (height, weight, waist circumferences and body composition analysis) were also taken. We measured body weight to the nearest $0.1 \mathrm{~kg}$ and height in light indoor clothes using a digital scale (model 763; Seca $\mathrm{GmbH} \& \mathrm{Co}, \mathrm{KG}$, Hamburg, Germany). Waist circumference was measured on a horizontal plane at the level of the iliac crest by an Ergonomic Circumference Measuring Tape (model 201; Seca GmbH \& Co, KG, Hamburg, Germany). Body mass index was calculated as weight in kilograms divided by the square of the height in meters. We assessed body fat mass by Bioelectrical Impedance Analysis (Body Stat Quad Scan, model 4000; Douglas Isle of Man, British Isles) after five minutes resting, with standard errors of estimate (accuracy) of $4.1 \%$. All anthropometric indices were obtained using the WHO standard procedures [17].

\subsection{Test Procedure}

Appropriate days to apply tests for the students attending first classes of Nutrition and Dietetics Department and Non-Medical Science departments were planned together with classroom consultant. After giving information about purpose, content and how to fulfill the test, they were distributed to the class on the day of appointment. All the participants informed about their answers based on research would remain confidential. Tests were applied under the supervision of researchers in their classrooms and it took nearly $15-20$ minutes.

\subsection{Data Analyses}

The data were evaluated by using SPSS for Windows 10.0 statistical package program. Student's test, chi-square, Pearson correlation tests and descriptive statistics were used in comparisons and $\mathrm{p}<0.05$ was considered significant. Both anthropometric measures and test scores of students were compared by groups and sex.

\subsection{Ethical Approval}

Ethical approval was taken by the decision of the Clinical Researches Ethics Committee of Ondokuz Mayis University with the number B.30.2.ODM.0.20.08/1553.

\section{Findings}

Hundred and thirty five $(\mathrm{n}=135,66.2 \%)$ students in the study group and $69(33.8 \%)$ students in the control group have taken place and the mean age of the groups were $20.141 \pm 1.68$ and 20,985 \pm 1.94 years respectively. Distribution of students by gender was as $160(78.4 \%)$ females and $44(21.6 \%)$ males. Some descriptive properties and test scores of the groups are compared at Table 1.

In terms of BMI, body weight and body fat percentage, students at study group had higher values than control group $(\mathrm{p}<0.05)$. There were no significant differences with respect to EAT, BDE and BAE tests scores between groups. 
All students who participated in the study are compared by gender for some descriptive characteristics and test scores in Table 2.

Boys had significantly higher values of BMI, age, height and weight than girls $(\mathrm{p}<0.05)$. Body fat percentage was within normal limits by gender and age-specific, but girls had significantly higher values than boys $(\mathrm{p}<$ $0.001)$. While EAT score was significantly higher in girls than boys $(\mathrm{p}<0.05)$, there were no significant differences between gender for other tests scores.

Table 1. Comparision of descriptive variables and test scores of the groups.

\begin{tabular}{cccc}
\hline Variable & Group & Mean \pm standard error & $\mathrm{p}$ \\
\hline \multirow{2}{*}{ BMI $\left(\mathrm{kg} / \mathrm{m}^{2}\right)$} & Study $^{1}$ & $22.208 \pm 0.308$ & \\
& Control $^{2}$ & $21.133 \pm 0.363$ & $0.017^{*}$ \\
Weight $(\mathrm{kg})$ & Study $^{1}$ & $62.542 \pm 1.029$ & \\
& Control $^{2}$ & $56.322 \pm 1.921$ & $0.002^{* *}$ \\
Body fat $(\%)$ & Study $^{1}$ & $19.854 \pm 0.938$ & \\
& Control $^{2}$ & $15.073 \pm 1.108$ & $0.000^{* *}$ \\
EAT score & Study $^{1}$ & $17.297 \pm 0.863$ & \\
& Control $^{2}$ & $17.138 \pm 1.254$ & 0.953 \\
BDE score & Study $^{1}$ & $9.416 \pm 0.644$ & \\
& Control $^{2}$ & $8.323 \pm 0.870$ & 0.489 \\
BAE score & Study $^{1}$ & $12.792 \pm 0.849$ & \multirow{2}{*}{0.534} \\
& Control $^{2}$ & $11.942 \pm 1.087$ & \\
\hline
\end{tabular}

p: ${ }^{*}$ significant; ${ }^{* *}$ very significant; Study group ${ }^{1}$ : Nutrition and Dietetics students; Control group ${ }^{2}$ : Non-medical students.

Table 2. Descriptive statistics and tests by gender.

\begin{tabular}{|c|c|c|c|}
\hline Variable & Group & Mean \pm standard error & $\mathrm{p}$ \\
\hline \multirow{2}{*}{ BMI $\left(\mathrm{kg} / \mathrm{m}^{2}\right)$} & Female & $21.455 \pm 0.262$ & \multirow{2}{*}{$0.001^{* *}$} \\
\hline & Male & $23.293 \pm 0.533$ & \\
\hline \multirow{2}{*}{ Age (year) } & Female & $20.263 \pm 0.148$ & \multirow{2}{*}{$0.043^{*}$} \\
\hline & Male & $20.886 \pm 0.221$ & \\
\hline \multirow{2}{*}{ Height (m) } & Female & $1.603 \pm 0.020$ & \multirow{2}{*}{$0.000^{*}$} \\
\hline & Male & $1.772 \pm 0.007$ & \\
\hline \multirow{2}{*}{ Weight (kg) } & Female & $56.965 \pm 0.970$ & \multirow{2}{*}{$0.000^{* *}$} \\
\hline & Male & $73.066 \pm 1.679$ & \\
\hline \multirow{2}{*}{ Body fat $(\%)$} & Female & $16.114 \pm 1.031$ & \multirow{2}{*}{$0.001^{* *}$} \\
\hline & Male & $10.275 \pm 1.348$ & \\
\hline \multirow{2}{*}{ EAT score } & Female & $18.170 \pm 0.796$ & \multirow{2}{*}{$0.011^{* *}$} \\
\hline & Male & $13.618 \pm 1.564$ & \\
\hline \multirow{2}{*}{ BDE score } & Female & $9.515 \pm 0.597$ & \multirow{2}{*}{0.127} \\
\hline & Male & $7.529 \pm 1.010$ & \\
\hline \multirow{2}{*}{ BAE score } & Female & $12.971 \pm 0.770$ & \multirow{2}{*}{0.118} \\
\hline & Male & $10.353 \pm 1.256$ & \\
\hline
\end{tabular}

p: "significant; ${ }^{* *}$ very significant. 
When students were grouped as underweight $\left(<18.5 \mathrm{~kg} / \mathrm{m}^{2}\right)$, normal $\left(18.5-24.9 \mathrm{~kg} / \mathrm{m}^{2}\right)$ or overweight $(\geq 25.0$ $\left.\mathrm{kg} / \mathrm{m}^{2}\right)$ according to their BMI, in both groups, the majority were found to be in the normal BMI range $(68.14 \%$ $(\mathrm{n}=92)$ in study group and $73.91 \%(\mathrm{n}=51)$ in control group). Relationship between BMI groups was investigated using Pearson's chi-square test statistic and there were not significant differences at the 5\% level.

The rate of students who got 30 and above points in Eating Attitude Test (EAT) were 6.7\% $(n=9)$ in study group and $5.8 \%(\mathrm{n}=4)$ in control group. There was no significance between groups $(\mathrm{p}>0.05)$.

The rate of students who got cut off (which is 17) and above points in Beck Depression Inventory (BDI) were $7.4 \%(n=10)$ in study group and $13.0 \%(n=9)$ in control group. There was no significance between groups $(\mathrm{p}>$ $0.05)$.

The rate of students according to gender who got 30 and above points in Eating Attitude Test (EAT) were 7.5\% $(\mathrm{n}=12)$ in females and $2.3 \%(\mathrm{n}=1)$ in males. The difference between genders was significant $(\mathrm{p}<0.001)$.

The rate of students according to gender who got 17 and above points in Back Depression Inventory (BDI) were $10.0 \%(n=16)$ in females and $6.8 \%(n=3)$ in males. The difference between genders was not significant $(\mathrm{p}>0.05)$.

Association between BMI and the scores of EAT, BDI and BAI are given in Table 3.

There were no significant association between BMI and the scores of EAT, BDI and BAI $(\mathrm{p}>0.05)$.

\section{Discussion}

Eating disorders are known as clinical presentations of disordered eating attitudes and behaviors as a result of the deterioration of the individual's body image. Especially adolescents and young women are accepted to be more susceptible to this disorder [18] [19]. Although eating disorders are known to be more common in girls, problems related with eating behaviors and weight cycling appear to be a growing issue for young men [1] [20].

In our study; BMI, body weight and body fat percentage values in students of Department of Nutrition and Dietetics were significantly higher than the values of control group (Table 1). In this case, career choices of students may have been affected by the problems students experienced related to the perception of body shape. It is well known that norms of the society on thinnes play important roles in the etiology of eating disorders. It is also known that some professions such asmodels, ballerinas, dancers and dietitians are more susceptible to develop eating disorders. It is reported that these professionals feels themselves under social pressure to be thin [21] [22]. Our findings indicate that training on Nutrition and Dietetics also makes individuals susceptible to eating disorders. In a study examined beliefs about and approaches to eating disorders in nutrition education faculties around the World concluded that eating disorders are a concern in nutrition faculties around the World [23].

The poor nutrition of 18- to 24-year-old adults is an important issue because they will soon enter the age range which has high risks for chronic disease [24]. Various factors affect young students' food selection. Some of them are a shortage of time, convenience, cost, taste, health, physical and social environment, and weight concern [25] [26]. Eating habits tend to become worse during high school and young adulthood [27] College students often do not meet dietary recommendations with respect to the various nutrients consumption. The typical college student diet is usually found to be high in fat and sodium but low in fruits and vegetables and so low in minerals and vitamins [27] [28].

In our study, male students have significantly higher in terms of BMI, body weight and height than females and female students have significantly higher in terms of percentage of body fat than male students (Table 2).

In across-sectional study which explored the prevalence of disordered eating attitudes, body shape concerns, and social anxiety and depressive symptoms in male and female medical students in China, significant relationships were observed between eating attitudes, body shape concern, social anxiety, depression, and body mass index. The most significant correlate of disordered eating attitudes was body shape concern for females, whereas

Table 3. Association statistics between BMI and the test scores of EAT, BDI and BAI.

\begin{tabular}{ccccc}
\hline Variables & Pearson correlation coefficient & t-test value & p-value & Account \\
BMI and EAT & 0.147 & 1.904 & 0.059 & 0.061 \\
BMI and BDI & 0.146 & 1.884 & Insignificant in 5\% & \\
BMI and BAI & -0.032 & -0.416 & 0.679 & Insignificant in 5\% \\
\hline
\end{tabular}


social anxiety and concern with muscle size and shape were most strongly correlated with distorted eating attitudes for males [4].

In our study, although study group has higher scores in all tests, there were no signifant difference in the scores of EAT, BDI and BAI (Table 1). When we compare female and male students in terms of the test scores, EAT scores of females $(18.170 \pm 0.79)$ were significantly higher than male students $(13.618 \pm 1.56)(\mathrm{p}=0.011)$. Test scores of female students were higher than male students in terms of BDI and BAI scores but the differences were not significant (Table 2). Association between BMI and the scores of EAT, BDI and BAI were analyzed with Pearson product-moment correlation and there were no significant association between them (Table 3). In a study performed on dietetic female students, there was a positive association between the anthropometric parameters with high scores in the EAT-26 and Body Shape Questionnaire (BSQ) questionnaires [29].

Eating disorders often coexist with mood problems, such as social anxiety and depression [7]. Celikel et al. [6] reported strong positive correlations between abnormal eating attitudes, anxiety, and depression in a sample of 267 female college students. Buchholz et al. [30] conducted a study with adolescent girls and found that social anxiety was a predictor of body dissatisfaction, whereas anxiety and body dissatisfaction were 2 risk factors closely associated with eating disorders. Similarly, a number of studies have reported that women with severe depression and anxiety are at a greater risk of developing an eating disorder than those without mood disorders [31] [32]. Kaye et al. [32] reported a lifetime prevalence of one or more anxiety disorders as a result of their study conducted with 672 eating disordered patients. Body dissatisfaction has consistently been identified as a risk factor for the development of depression [33], suicidal ideation [33]-[35] and social anxiety [30]. Although many of these studies have been conducted with women, the study by Buyokgoze-Kavas [36], with male and female participants reported no sex differences in eating attitudes and comorbid depression. It is clearly apparent that eating disorders have far reaching physical and emotional consequences.

In our study, the rate of students who got 30 and above points in EAT were $6.7 \%$ in study group and $5.8 \%$ in control group $(p>0.05)$. The rate of students according to gender who got above cut off points in EAT were $7.5 \%$ in females and $2.3 \%$ in males. The difference between genders was significant $(\mathrm{p}<0.001)$.

When we examined the students who got 17 and above points in BDI in terms of groups and genders, we didn't find significant differences between neither groups nor genders.

In a study conducted to search in dietary trends and eating habits in a group of college students, several sex differences were observed with respect to anthropometric measurements, choices of diets, sources of nutritional knowledge and nutrition attitudes. It was concluded that dietitians and other health professionals experienced in this field should take these differences into account when developing nutrition education materials and designing nutrition intervention programs for college students and other young adults [25].

Similar to this study, there were significant differences between genders in terms of anthropometric measurements in our study (Table 2). Despite male students had higher values in body weight and BMI than female students, EAT scores of females were higher than male students. This finding is consistent with other studies showing that young women are more susceptible with respect to eating attitudes and related comorbid disorders.

The majority of the students were found to be in the normal BMI range in both groups (\%68.14 in study group and \%73.91 in control group). But students in study grup had significantly higher values in terms of body weight, BMI and percent of body fat. In a study conducted to evaluate the relationship between changes in eating behavior associated with dissatisfaction with body image and the nutritional status of female university students of nutrition, it was found out that the students who were overweight, with elevated body fat percentage $(\% \mathrm{BF})$ and waist circumference (WC) had a 5 - 9 times greater risk of change in eating habits [29]. And concluded that the future dietitians who were overweight, with increased body fat and waist circumference were more likely to be dissatisfied with their body image and develop eating disorders. As in our study, use of other anthropometric parameters, in addition to BMI, may prove useful in screening individuals susceptible to the emergence of excessive concerns with weight and diet.

\section{Conclusions}

Weight-specific socioenvironmental, personal, and behavioral variables are strong and consistent predictors of overweight status, binge eating and extreme weight-control behaviors in adolescence [37] [38].

In our study, although BMI and the \% of body fat based on age and gender were within normal limits, they were significantly higher than the control group in Nutrition and Dietetics students, which suggested that stu- 
dents who had obsessions with body image might tend to choose training on Nutrition and Dietetics. Though there were no significant differences among the scores of EAT, BDI and BAI, EAT and BDI scores of female students were higher than male students. These findings also suggested that young women were more susceptible to disorders related with body image, eating attitudes and depression.

This study also brings to mind the importance of psychodynamic and early childhood experiences in choosing an occupation. We have reached the conclusion that sociocultural factors, weight-related social pressures, occupational training, personal weight concerns, and unhealthy weight-control behaviors added to early childhood experiences make especially young girls more susceptible to eating disorders and related psychopathologies. But there is a need for extensive new studies.

\section{Acknowledgements}

We thank all the students participating in to this study. We did not have any financial support for his study.

\section{References}

[1] Seymour, M., Hoerr, S.L. and Huang, Y. (1997) Inappropriate Dieting Behaviors and Related Lifestyle Factors in Young Adults: Are College Students Different? Journal of Nutrition Education, 29, 21-25. http://dx.doi.org/10.1016/S0022-3182(97)70142-0

[2] Schulken, E.D., Pinciaro, P.J., Sawyer, R.G., Jensen, J.G. and Hoban, M.T. (1997) Sorority's Women's Body Size Perceptions and Their Weight-Related Attitudes and Behaviors. Journal of the American College of Cardiology, 46, 69-74. http://dx.doi.org/10.1080/07448489709595590

[3] Hoek, H.W. and van Hoeken D. (2003) Review of the Prevalence and Incidence of Eating Disorders. International Journal of Eating Disorders, 34, 383-396. http://dx.doi.org/10.1002/eat.10222

[4] Liao, Y., Knoesenb, N.P., Castleb, D.J., Tanga, J., Dengd, Y., Bookunb, R., et al. (2010) Symptoms of Disordered Eating, Body Shape, and Mood Concerns in Male and Female Chinese Medical Students. Comprehensive Psychiatry, 51, 516-523. http://dx.doi.org/10.1016/j.comppsych.2009.11.007

[5] Kuğu, N., Akyüz, G. and Doğan, O. (2002) Üniversite öğrencilerinde yeme bozukluklarının yaygınlığı ve yeme bozukluğu olanlarda benlik saygısı, aile işlevleri, çocukluk çağı istismarı ve ihmalinin araştırılması. Psikiyatri Psikoloji Psikofarmakoloji (3P) Dergisi, 10, 255-266.

[6] Çelikel, F.C., Cumurcu, B.E., Koç, M., Etikan, İ. and Yücel, B. (2008) Psychologic Correlates of Eating Attitudes in Turkish Female College Students. Comprehensive Psychiatry, 49, 188-194. http://dx.doi.org/10.1016/j.comppsych.2007.09.003

[7] Özenoğlu, A., Kumcağı, H., Tokay, A., Alakus, K., Can, G., Ince, G., et al. (2013) Relationships of Eating Attitudes with Sociodemographic, Psychologic and Nutritional Factors in University Students Attending First Classes. Turkiye Klinikleri Journal of Medical Sciences, 33, 972-980. http://dx.doi.org/10.5336/medsci.2012-31203

[8] Baş, M., Aşçi, F.H., Karabudak, E. and Kızıltan, G. (2004) Eating Attitudes among Turkish Adolescents. Adolescence, 39, 593-599.

[9] Erol, A., Toprak, G. and Yazici, F. (2002) Predicting Factors of Eating Disorders and General Psychological Symptoms in Female College Students. Turkish Journal of Psychiatry, 13, 48-57.

[10] Binnur, Y. (2011) The Paradigm Shift of Vocational Guidance and Career Counseling and Its Implications for Turkey: An Evaluation from Past to Future. Educational Sciences: Theory \& Practice, 11, 19-26.

[11] Garner, D.M. and Garfinkel, P.E. (1979) The Eating Attitudes Test. An Index of Symptoms of Anorexia Nervosa. Psychological Medicine, 9, 273-279. http://dx.doi.org/10.1017/S0033291700030762

[12] Savasir, I. and Erol, N. (1989) Yeme Tutum Testi: Anoreksiya Nevroza Belirtileri İndeksi. Türk Psikoloji Dergisi, 7 , 19-25.

[13] Beck, A.T., Ward, C.H., Mendelson, M., Mock, J. and Erbaugh, J. (1961) An Inventory for Measuring Depression. Archives of General Psychiatry, 4, 561-571. http://dx.doi.org/10.1001/archpsyc.1961.01710120031004

[14] Hisli, N. (1989) Beck Depresyon Envanterinin üniversite öğrencileri için geçerliliği ve güvenilirliği. Türk Psikoloji Dergisi, 6, 3-13.

[15] Beck, A.T., Epstein, N., Brown, G. and Steer, R.A. (1988) An Inventory for Measuring Clinical Anxiety: Psychometric Properties. Journal of Consulting and Clinical Psychology, 56, 893-897. http://dx.doi.org/10.1037/0022-006X.56.6.893

[16] Ulusoy, M., Sahin, N.H. and Erkmen, H. (1998) Turkish Version of the Beck Anxiety Inventory. Journal of Cognitive Psychotherapy, 12, 163-172.

[17] World Health Organization Physical Status (1995) The Use 478 and Interpretation of Anthropometry. Technical Report 
479 Series No. 854, WHO, Geneva.

[18] Gonçalves, J.A., Moreira, E.A., Trindade, E.B. and Fiates, G.M. (2013) Eating Disorders in Childhood and Adolescence. Revista Paulista de Pediatria, 31, 96-103. http://dx.doi.org/10.1590/S0103-05822013000100016

[19] Hoek, H.W. (2006) Incidence, Prevalence and Mortality of Anorexia Nervosa and Other Eating Disorders. Current Opinion in Psychiatry, 19, 389-394. http://dx.doi.org/10.1097/01.yco.0000228759.95237.78

[20] Woodside, D.B., Arfinake, P.E., Lin, E., Goering, P., Kaplan, A.S., Goldbloom, D.S., et al. (2001) Comparisons of Men with Full or Partial Eating Disorders, Men without Eating Disorders and Women with Eating Disorders in the Community. American Journal of Psychiatry, 158, 570-574. http://dx.doi.org/10.1176/appi.ajp.158.4.570

[21] Ricciardelli, L.A. and McCabe, M.P. (2003) Sociocultural and Individual Influences on Muscle Gain and Weight Loss Strategies among Adolescent Boys and Girls. Psychology in the Schools, 40, 209-224. http://dx.doi.org/10.1002/pits.10075

[22] Tozzi, F., Sullivan, P.F., Fear, J.L., McKenzie, J. and Bulik, C.M. (2003) Causes and Recovery in Anorexia Nervosa: The Patients Perspective. International Journal of Eating Disorders, 33, 143-154. http://dx.doi.org/10.1002/eat.10120

[23] Drummond, D. and Hare, M.S. (2012) Dietitians and Eating Disorders: An International Issue. Canadian Journal of Dietetic Practice and Research, 73, 86-90. http://dx.doi.org/10.3148/73.2.2012.86

[24] Winkleby, M.A. and Cubbin, C. (2004) Changing Patterns in Health Behaviors and Risk Factors Related to Chronic Diseases, 1990-2000. American Journal of Health Promotion, 19, 19-27. http://dx.doi.org/10.4278/0890-1171-19.1.19

[25] Davy, S.R., Benes, B.A. and Driskell, J.A. (2006) Sex Differences in Dieting Trends, Eating Habits, and Nutrition Beliefs of a Group of Midwestern College Students. Journal of the American Dietetic Association, 106, 1673-1677. http://dx.doi.org/10.1016/j.jada.2006.07.017

[26] Buscher, L.A., Martin, K.A. and Crocker, S. (2001) Point-of-Purchase Messages Framed in Terms of Cost, Convenience, Taste, and Energy Improve Healthful Snack Selection in a College Foodservice Setting. Journal of the American Dietetic Association, 101, 909-913. http://dx.doi.org/10.1016/S0002-8223(01)00223-1

[27] Galore, S.R., Walker, C. and Chandler, A. (1993) Brief Communication: Dietary Habits of First-Year Medical Students as Determined by Computer Software Analysis of Three Day Food Records. Journal of the American College of Nutrition, 12, 517-520. http://dx.doi.org/10.1080/07315724.1993.10718345

[28] Pérez-Gallardo, L., Mingo Gómez, T., Bayona Marzo, I., Ferrer Pascual, M.Á., Marquez Calle, E., Rámirez Domínguez, R., et al. (2015) Diet Quality in College Students with Different Academic Profile. Nutricion Hospitalaria, 31, 2230-2239.

[29] Silva, J.D., Silva, A.B., de Oliveira, A.V. and Nemer, A.S. (2012) Influence of the Nutritional Status in the Risk of Eating Disorders among Female University Students of Nutrition: Eating Patterns and Nutritional Status. Ciência \& Saúde Coletiva, 17, 3399-3406. http://dx.doi.org/10.1590/S1413-81232012001200024

[30] Buchholz, A., Henderson, K.A., Hounsell, P.A., Wagner, A., Norris, M. and Spettigue, W. (2007) Self-Silencing in a Clinical Sample of Female Adolescents with Eating Disorders. Journal of the Canadian Academy of Child and Adolescent Psychiatry, 16, 158-163.

[31] Morgan, J., Scholtz, S., Lacey, H. and Conway, G. (2008) The Prevalence of Eating Disorders in Women with Facial Hirsutism: An Epidemiological Cohort Study. International Journal of Eating Disorders, 41, 427-431. http://dx.doi.org/10.1002/eat.20527

[32] Kaye, W.H., Bulik, C.M., Thornton, L., Barbarich, N. and Masters, K. (2004) Comorbidity of Anxiety Disorders with Anorexia and Bulimia Nervosa. American Journal of Psychiatry, 161, 2215-2221. http://dx.doi.org/10.1176/appi.ajp.161.12.2215

[33] Paxton, S.J., Neumark-Sztainer, D., Hannan, P.J. and Eisenberg, M.E. (2006) Body Dissatisfaction Prospectively Predicts Depressive Mood and Low Self-Esteem in Adolescent Girls and Boys. Journal of Clinical Child \& Adolescent Psychology, 35, 539-549. http://dx.doi.org/10.1207/s15374424jccp3504_5

[34] Rodriguez-Cano, T., Beato-Fernandez, L. and Llario, A.B. (2006) Body Dissatisfaction as a Predictor of Self-Reported Suicide Attempts in Adolescents: A Spanish Community Prospective Study. Journal of Adolescent Health, 38, 684-688. http://dx.doi.org/10.1016/j.jadohealth.2005.08.003

[35] Brausch, A.M. and Muehlenkamp, J.J. (2007) Body Image and Suicidal Ideation in Adolescents. Body Image, 4, 207212. http://dx.doi.org/10.1016/j.bodyim.2007.02.001

[36] Buyukgoze-Kavas, A. (2007) Eating Attitudes and Depression in a Turkish Sample. European Eating Disorders Review, 15, 305-310. http://dx.doi.org/10.1002/erv.776

[37] Neumark-Sztainer, D.R., Wall, M.M., Haines, J.I., Story, M.T., Sherwood, N.E. and van den Berg, P.A. (2007) Shared Risk and Protective Factors for Overweight and Disordered Eating in Adolescents. American Journal of Preventive 
Medicine, 33, 359-369. http://dx.doi.org/10.1016/j.amepre.2007.07.031

[38] Mahn, H.M. and Lordly, D. (2015) A Review of Eating Disorders and Disordered Eating amongst Nutrition Students and Dietetic Professionals. Canadian Journal of Dietetic Practice and Research, 76, 38-43.

http://dx.doi.org/10.3148/cjdpr-2014-031 